\title{
Dr. Margaret Anne Carter, Josie Santomauro: Pirates: An Early- Years Group Program for Developing Social Understanding and Social Competence for Children with Autism Spectrum Disorders and Related Challenges
}

\author{
Autism Asperger Publishing Company, Shawnee Mission, KS, 2007, 352 pp., \$29.95
}

\author{
Kathleen Koenig \\ Published online: 25 July 2009 \\ (C) Springer Science+Business Media, LLC 2009
}

This volume is, as the title makes quite explicit, a curriculum for helping preschool to third grade children with ASDs address social impairment challenges. The curriculum adopts the theme of Pirates (captains, buccaneers, voyages, booty), and the cover features two adorable children dressed up in pirate costumes. The Pirate theme is carried throughout every chapter, describing adventures, pirate dreams, loot sharing and chanties for the children to learn and sing. The behavioral expectations for the children such as "considerate hands" or "courteous hand signals" are taught through discussions with the children, using media to support the discussion at the "Captain's" discretion. An emphasis is placed on the idea that not only the group leader but other children do not like misbehavior, and that once the child understands this, he or she will be motivated to modify behavior.

The book contains relaxation sessions using visualization for the children. The preschool version begins with "close your eyes and sit in a comfortable position...imagine that you are a Pirate standing on the deck of a sailing ship. On one side is the ocean as far as you can see...in front of you is a hammock (p. 29)." The session continues "you feel your legs turn soft like jelly," "In your dream a friendly octopus comes to you....sits up on its tentacles and talks to you....(p. 30)" The session goes on and on in the same vein, asking the children to use their imagination, and interpret metaphor and simile.

The book is divided into sections for preschool, kindergarten, first, second and third grade. Each set of lessons continues the pirate theme, having children make pirate decorations, and make up pirate stories and play pirate games. The issues of learning to share, take-turns, learn emotions vocabulary, handle bullying, stay in one's personal space, and other social skills are mentioned incidentally and briefly in each chapter, and the strategy for teaching is discussion. For example, second graders complete a work sheet based on what they learned that day, and sometimes complete work sheets in which they write down responses to "I wish...", "I am a good friend when...(p. 196)" The children read their responses to each other, presumably so they can discuss the answers.

There is not enough space to describe the amazingly offthe-mark activities included in this volume. Suffice it to say, it is a near perfect example of an attractively packaged curriculum with absolutely no relevance for teaching social skills to children with autism spectrum conditions. There is no mention of how to design or implement behavioral strategies based on what works for kids for ASDs. The very brief reference list includes mainstream, mass-market titles, and not one substantial volume geared towards understanding the cognitive and social deficits of children with ASDs, or the evidence-based methods available for teaching. The list of resources is entirely children's books about pirates. In short, this curriculum is most appropriate for children with ASDs who have above-average cognitive skills; above average receptive/expressive language; the ability to understand symbolism, metaphor and simile; good writing skills; a capacity for rich imaginative thinking and play; the ability to understand and follow behavior rules based on discussions; the ability to regulate behavior and emotions based on discussion using pirate themes and language, and to generalize what is learned to other environments.
K. Koenig ( $\square)$

Yale Child Study Center, New Haven, CT, USA

e-mail: kathy.koenig@yale.edu 